\title{
Power Balance of a Hybrid Power Source in a Power Plant for a Small Propulsion Aircraft
}

\author{
Elena Bataller-Planes*, Nieves Lapena-Rey*, Jonay Mosquera*, Fortunato Ortí, J. A. Oliver**, O. García**, \\ F. Moreno**, J. Portilla**, Y. Torroja**, M. Vasic ${ }^{* *}$, S.C. Huerta**, M. Trocki**, P. Zumel ${ }^{* *}$ and J.A. Cobos** \\ ${ }^{*}$ Boeing Research \& Technology Europe S.L., Madrid, Spain \\ ${ }^{* *}$ Universidad Politécnica de Madrid - Centro de Electrónica Industrial, Madrid, Spain
}

\begin{abstract}
This paper analyzes two different architectures for a hybrid power source comprising a PEM (Polymer Electrolyte Membrane) fuel cell and a $\mathrm{Li}$ ion battery. The hybrid power source feeds the propulsion motor of an all electrical aircraft, the Boeing Fuel Cell Demonstrator. The architectures are an unregulated and a regulated hybrid power source. The regulation is achieved by means of a controllable series boost converter (SBC) connected in series with the fuel cell. Both architectures have been simulated, implemented and tested in the Boeing Fuel Cell Demonstrator Airplane.
\end{abstract}

\section{INTRODUCTION}

The Boeing Fuel Cell Demonstrator is a manned full electrical aircraft that flies level with only the energy of a PEM fuel cell. It is an example, not only of an all electrical aircraft, but also of an environmentally friendly aircraft, because the only exhaust product is water vapor.

The airplane has two levels of power demand: a high power demand for take-off and climb and a low power demand for cruise (Fig. 1). Since fuel cells have relatively low specific powers, the fuel cell of the Boeing Fuel Cell Demonstrator Airplane was sized for the cruise power demand. The additional power required for take-off and climb is provided by a $\mathrm{Li}$ ion battery, that has higher power density but lower energy density than the fuel cell. Therefore, the Boeing Fuel Cell Demonstrator Airplane has a hybrid power source comprising a PEM fuel cell and a Li ion battery.

The objective of this paper is the analysis of two electrical architectures for this hybrid power source, unregulated and regulated.

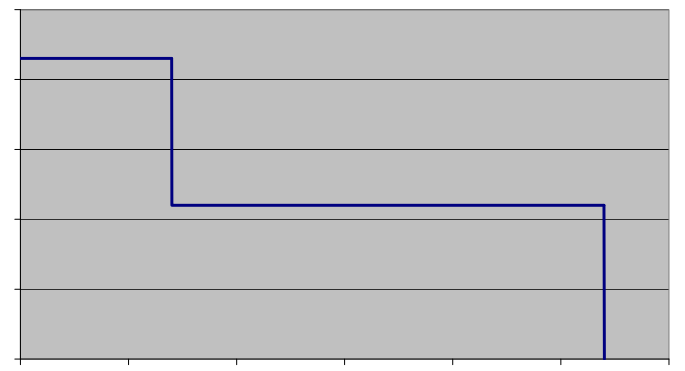

Figure 1. Simplified power profile for the flight mission

\section{POWER PLANT DESCRIPTION}

The airplane is equipped with a dc brushless motor comprising an inverter and an electrical motor, that drives a variable pitch propeller. The motor power is proportional to the torque generated by the motor and the rotational speed set by the propeller pitch angle. The pilot controls the torque magnitude by means of the throttle lever and the rotational speed by setting it in the propeller pitch controller. The throttle lever input is processed by a controller (the power management and distribution control board) that sends the torque command to the motor inverter. The rotational speed is controlled by the propeller control unit.

During take-off and climb both the battery and the fuel cell supply power to the electric motor. During the cruise the battery is disconnected and the fuel cell supplies all the power required to maintain a straight level flight. The battery is not recharged in flight.

The fuel cell system maximum output power is $24 \mathrm{~kW}$ gross. The output voltage of the fuel cell system varies following its polarization curve (V vs. I) from approximately $320 \mathrm{~V}$ at open circuit voltage (OCV) to 215 $\mathrm{V}$ at full power.

The battery can supply a maximum continuous power in the range of $50-75 \mathrm{~kW}$. The battery voltage depends on its state of charge and current. The nominal voltage is 237 $\mathrm{V}$, the open circuit voltage when the battery is fully charged is $264 \mathrm{~V}$ and the battery can discharge down to approximately $215 \mathrm{~V}$.

The propulsion motor consumes approximately $40 \mathrm{~kW}$ during take-off and climb (approximately $7 \mathrm{~min}$ ). The total power delivered by the sources during take-off and climb is approximately $43 \mathrm{~kW}$. Additional loads include the fuel cell auxiliary equipment and small actuators, controllers and other electrical equipment. The detailed descriptions of the power sources and the airplane's subsystems are given elsewhere [2-3].

\section{PROPOSED ARCHITECTURES}

Two different architectures have been analyzed and thoroughly tested in the Boeing Fuel Cell Demonstrator Airplane.

In the first architecture (Fig. 2), the hybrid power source comprises the fuel cell and the battery connected in parallel to a distribution bus by means of OR'ing diodes.

In the second architecture (Fig. 3), a series boost converter is added to the bus in series with the fuel cell. The series boost converter comprises six individual quasi-resonant 
forward converters in parallel, in a master-slave configuration. Individual OR'ing diodes are added to each converter. The serial boost converter, comprising the converters and the OR'ing diodes, is by-passed by a power diode. When the series boost converter is disabled, the current flows through the by-passing diode.

The advantage of using a dc-dc converter in series with the fuel cell rather than in parallel, to control the power balance is that, the dc-dc converter handles a fraction of the fuel cell power $(3 \mathrm{~kW})$. The serial connection of the dc-dc implies lower losses and, therefore, lower size and weight of the converter. In the demonstrator airplane, the fraction of the fuel cell power processed by the dc-dc converter is $15 \%$ in the worst case scenario.

\section{A. Power balance for an unregulated architecture}

The bus voltage and the power delivered by each source is a function of the demanded load and the state of charge of the battery. The simplified power flight profile of the Boeing Fuel Cell Demonstrator Airplane is shown in Fig. 1. During the high power demand phase, more than half of the power is drawn from the battery. As the battery discharges, the battery, bus and fuel cell voltages decrease. Therefore, the fuel cell power increases (the lower the voltage of the fuel cell, the higher its current and its power), whereas the battery power decreases (Fig. 7).

With this architecture, the fuel cell is operated below its maximum power output capabilities in all conditions.

\section{B. Power balance for a regulated architecture}

Regulating the power distribution can enhance the total energy of the hybrid power source by saving the battery energy. The power balance can be achieved by regulating the output voltage of a converter connected in series with the fuel cell to the distribution bus (Fig. 2). The output voltage of this converter sets the bus voltage within the limits of its operating range.

For a given bus voltage, the SBC allows the fuel cell to work at a lower voltage, i.e., at a higher power. In this way, the battery works at a lower power level and lasts

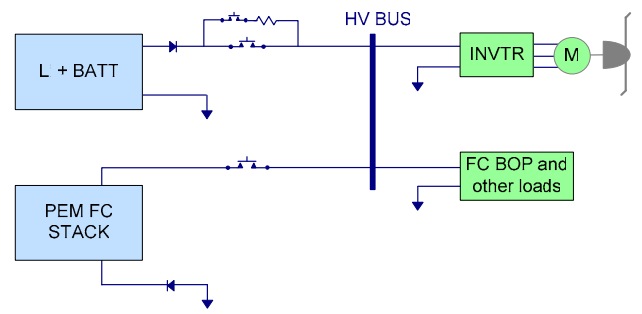

Figure 2. Power architecture with unregulated hybrid power source

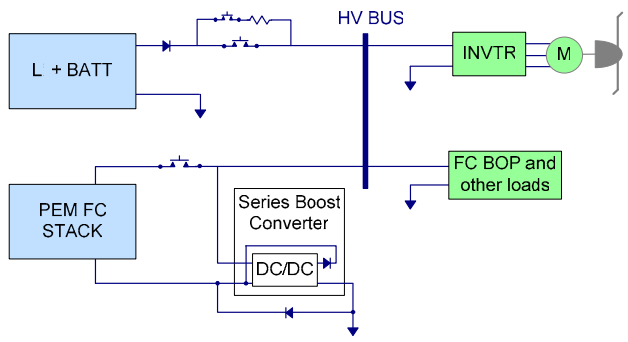

Figure 3. Power architecture with regulated hybrid power source longer. Additionally, the battery is discharged at a lower current, which normally results in a higher useful capacity.

The output voltage of the converter is regulated through a control loop that maximizes the total energy delivered by the hybrid power source in such a way that, for a given load, the power delivered by the fuel cell, and so its current, is maximized.

\section{SYSTEM DESCRIPTION}

Both proposed architectures were implemented in the Boeing Fuel Cell Demonstrator Airplane within the power management and distribution box (PMAD).

\section{A. PMAD functionalities}

This box (Fig. 4) is the integrator element of the airplane electrical system, and is in charge of distributing the power from the sources to the loads and of managing the power flow and protections. The power flow and protections management comprises:

- the control of the wake-up/shut-down sequences;

- the protection of the different components;

- the interface with the pilot through the instrumentation panel;

- the regulation of the power balance between the fuel cell and the battery;

- $\quad$ the command of the propulsion motor by means of the throttle input and the configuration and state of the electrical system.

The regulation of the power balance between the sources can be enabled or disabled to obtain the regulated and unregulated architectures, respectively. To disable this regulation, the SBC is disabled, and the fuel cell current would flow through the by-passing diode (Fig. 3). When using the regulated architecture, the SBC is only enabled when both sources are connected to the bus.

\section{B. PMAD control board}

The PMAD box is controlled by an internal control board (Fig. 5). The heart of the PMAD control board is an FPGA (Field Programmable Gate Array) that implements the digital control loops in charge of the SBC and throttle regulations, and the controls in charge of the sequences, protections and interface with the pilot. The control board comprises sensing and analog interface circuitry (sensors signal conditioning, display signal conditioning, SBC command reference and throttle interface circuit), digital circuitry (ADCs, DACs, FPGA, Flash and PROM memories, clocks, digital I/O interface and SSPCs (solid state power controllers) state interface) and power circuitry (power supplies conditioning, contactors commands circuit and SSPCs). The FPGA receives the analog and digital information from the sensors (current and voltage measurements) and the pilot (switches and throttle lever position), processes them, and commands the power contactors, the solid state power controllers, the LEDs and the digital displays on the instrumentation panel, the enabling and command of the SBC and the torque request to the propulsion motor inverter. 


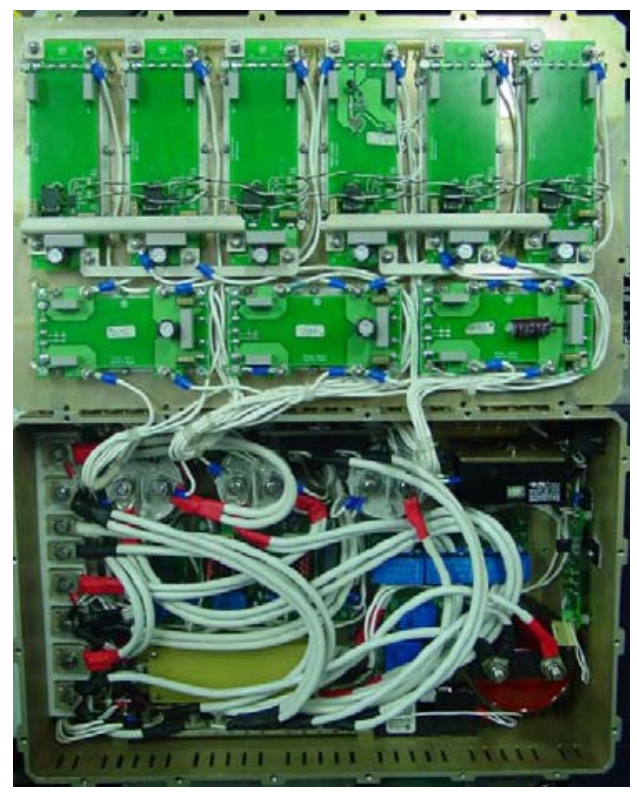

Figure 4. PMAD box

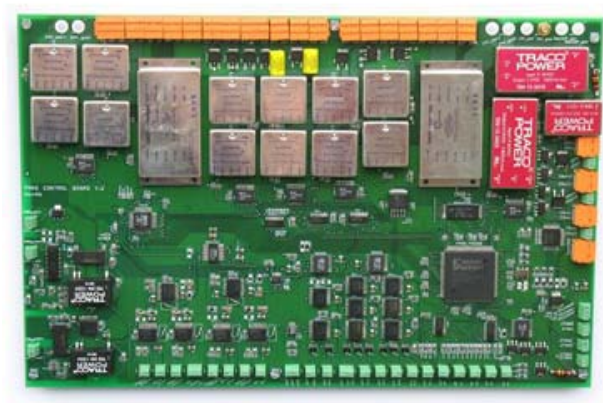

Figure 5. PMAD control board

\section{Sequences and protections}

The start-up and shut-down procedures are controlled through a state machine, that also protects the sources and the propulsion motor inverter.

A low voltage, low power, battery feeds the PMAD control board and afterwards allows the start of the Li ion battery by powering its internal controller. The battery is connected to the distribution bus through a classical softstart (Fig. 2), gradually charging the capacitors connected to the bus (approximately $8 \mathrm{mF}$ ). Once the capacitors are charged, the battery is connected to the bus through a power contactor. Once the bus is energized, the fuel cell balance of plant gets powered and allows the start of the fuel cell system. The fuel cell stacks are directly connected to the bus through an additional power contactor.

The state machine monitors the electrical variables to detect electrical faults and uses the same power contactors to protect the sources and the inverter against overcurrents, negative currents in the sources, fuel cell current steps, under-voltages, over-voltages and regenerative operation of the motor. The low power lines are protected against over-currents mainly by SSPCs.

\section{Control loops}

The output voltage of the SBC is regulated through a control loop that maximizes the fuel cell power, and, therefore, the fuel cell current.

In order to determine the desired fuel cell and battery currents, the load current is compared to the maximum fuel cell current. If the load current is lower than the maximum fuel cell current, the hybrid system is forced to work with the fuel cell supplying all the demanded current and the battery supplying no current. Otherwise, the hybrid system is forced to work with the fuel cell delivering its maximum current and the battery delivering the rest of the load current.

The control loop was first tested using the PEM fuel cell, a laboratory power supply replacing the battery and a programmable load unit replacing the propulsion motor and inverter. In this test, the fuel cell works at $20 \mathrm{~A}$ if the load is equal or higher than $20 \mathrm{~A}$. Otherwise, the control makes the fuel cell supply the demanded current.

At the beginning the load current is lower than $20 \mathrm{~A}$, therefore, the SBC output voltage is set so the fuel cell delivers all the current and the laboratory power supply delivers no current. Afterwards, a positive current step is applied and the control increases the SBC output voltage to make the fuel cell deliver 20A and the laboratory power supply deliver the rest of the load current (Fig. 6).

Once the battery discharges down to the point where the minimum output voltage of the $\mathrm{SBC}$ is reached, the bus voltage is fixed by the fuel cell. Since the battery continues discharging, it is not longer able to supply the difference between the continuous loads power and the maximum fuel cell power, so the fuel cell would have to operate over its capabilities. To avoid this, a control law that decreases the main load power (the propulsion motor) was implemented in the throttle control of the demonstrator airplane.

The throttle control receives the throttle lever position, conditions this information and sends a proportional torque command to the propulsion motor inverter. If the throttle demand implies the propulsion motor power being higher than the power allocated in the sources, the control automatically reduces the torque command to reach a balance between electrical sources and electrical loads. This is done by means of two control loops that compare the measured sources currents with their maximum allowable currents, respectively.

Additionally, the throttle control processes the torque

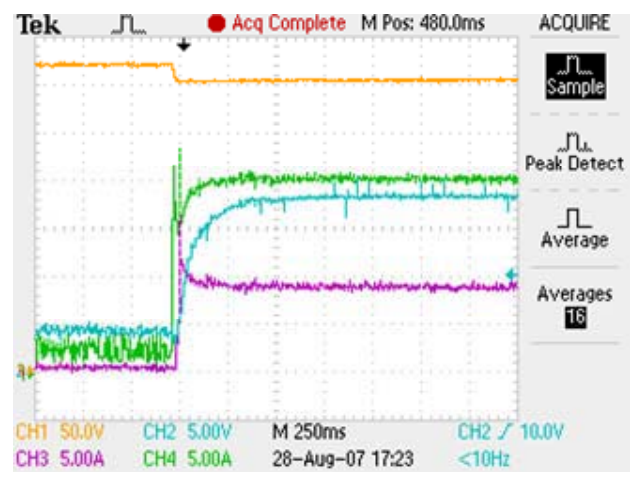

Figure 6. Validation of series boost converter control loop (CH1 is the bus voltage, $\mathrm{CH} 2$ is the $\mathrm{SBC}$ output voltage, $\mathrm{CH} 3$ is the power supply current, $\mathrm{CH} 4$ is the fuel cell current) 
command through a slew ramp limiter in order to obtain smooth power change rates. Since fuel cells have relatively slow dynamics, the slew ramp limiter avoids exceeding the maximum allowable rate of power change per unit time.

The SBC control maximizes the fuel cell current and the throttle control can decrease both the fuel cell or the battery currents. Since, these controls can influence the sources currents, there is a link between the SBC control and the fuel cell current control loop of the throttle control so both cannot work at the same time. A logic law manages when each one should operate. The throttle limitation would start operating once the SBC output voltage decreases down to its minimum while the load is demanding a constant power.

\section{SIMUlATIONS AND TESTING}

Both architectures were simulated prior to implementing them in the electrical system. The model for the hybrid power system was developed in Simplorer and the model for the control was developed in Simulink (Matlab) to account for its digital hardware implementation effects (resolution and finite arithmetic). The co-simulation of the whole system, power architecture and control, allowed the evaluation of the system in all different operative conditions and faults. The model was also useful to fine tune the controls and protections before setting up the tests bench. The fuel cell and the battery were modeled based on experimental data. The polarization curve was used for the fuel cell steady behavior and results of small signal source impedance tests were used for the fuel cell dynamic behavior. The discharge curves of the battery cells at different constant currents were used to build the battery model.

The models of all individual components (fuel cell, battery, dc-dc converters, motor, SSPCs, remote controlled contactors, etc) were validated prior their integration in the global model.

In order to validate the models the simulation results were cross checked with tests results of a typical flight mission.

After the implementation, both architectures were tested by reproducing the power profile of the flight mission. All electrical parameters were recorded along with the PMAD temperatures.

The tests were done statically either by replacing the propeller of the demonstrator by a controllable hydraulic brake or using the propeller with the aircraft braked.

In the first case, the measurements were done by voltage and Hall Effect current probes, were conditioned by acquisition cards and recorded in a computer. Data was acquired at $0.17 \mathrm{~Hz}$.

In the second case, the acquisitions were taken in the PMAD box. Measurements were done by internal Hall Effect current and voltage probes, and were conditioned and recorded by the PMAD control. A Flash memory controlled by the FPGA of the PMAD control board was used to record the data. Data was acquired at $1 \mathrm{~Hz}$.

In both cases, the bus, fuel cell and battery voltages, and the motor inverter, fuel cell and battery currents were acquired. The motor, fuel cell and battery powers were calculated. The motor powers shown correspond to the power at the input of the inverter.

\section{A. Unregulated architecture}

Fig. 7 shows the motor, fuel cell and battery powers, with a natural power balance between the battery and the fuel cell. The motor power is approximately $40 \mathrm{~kW}$. The battery supplies a bit more than half of the power and the proportional power supplied by the fuel cell increases with time due to the battery discharge. Fig. 8 shows the motor, fuel cell and battery currents. Fig. 9 shows the bus voltage, that coincides with the fuel cell and battery voltages. The fuel cell current and power increase and the bus voltage decreases as the battery discharges.

Fig. 10 and Fig. 11 show the comparison between simulated and measured powers and battery capacity, respectively. The simulation results are in close agreement with the test results.
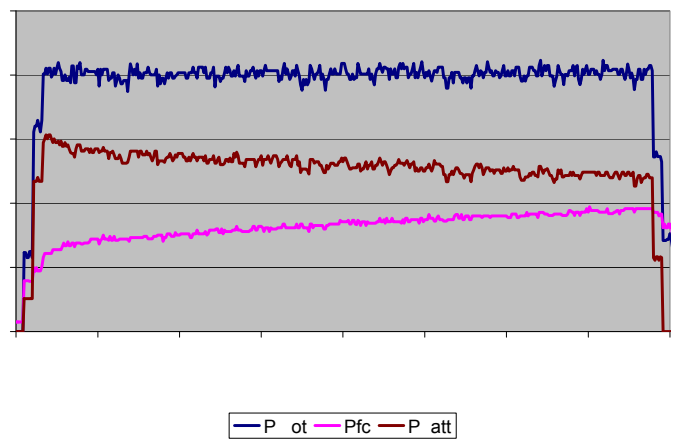

Figure 7. Measured powers with unregulated hybrid source

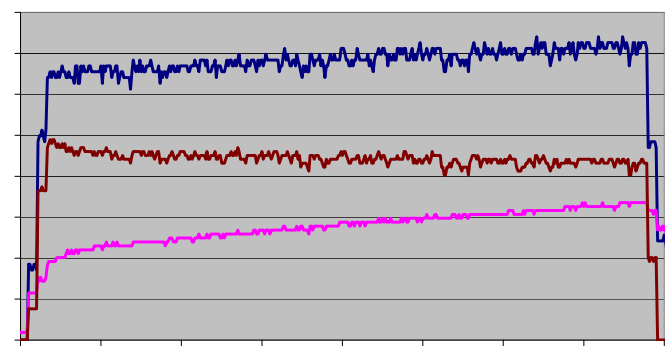

-1 ot - Ifc -1 att

Figure 8. Measured currents with unregulated hybrid source
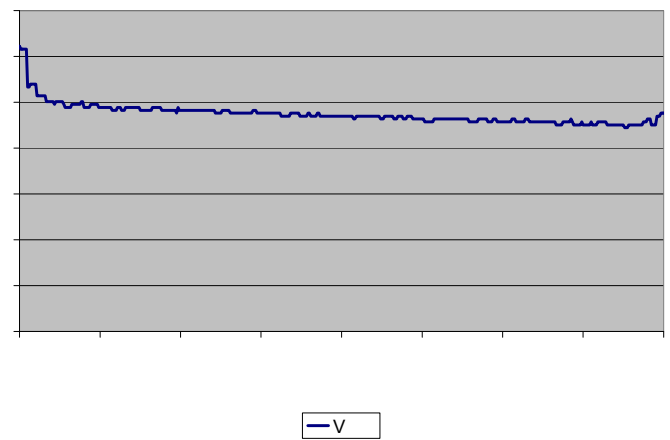

Figure 9. Measured voltage with unregulated hybrid source 


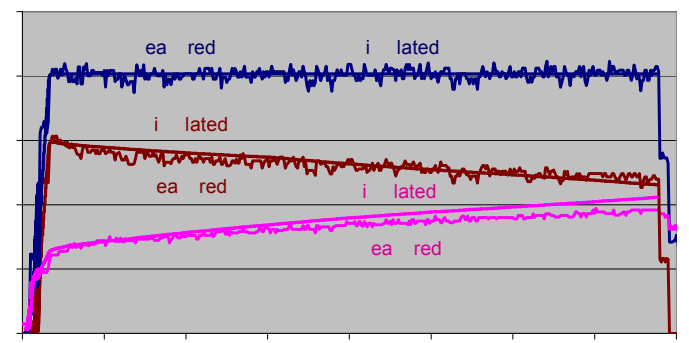

-P ot $-\mathrm{Pfc}-\mathrm{P}$ att

Figure 10. Comparison of simulation and test results for powers for the unregulated architecture during take-off and climb

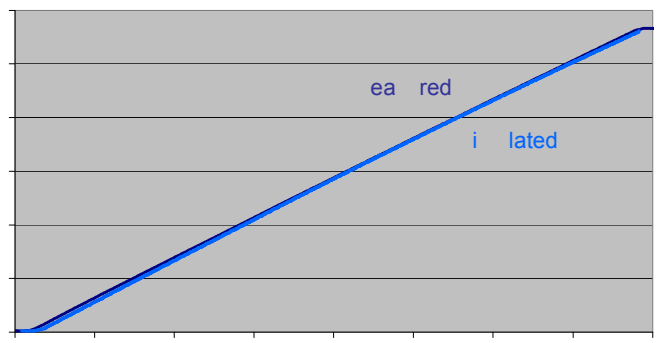

$$
\text { - att }
$$

Figure 11. Comparison of simulation and test results for battery capacity for the unregulated architecture during take-off and climb

\section{B. Regulated architecture}

Fig. 12 shows the motor, fuel cell and battery powers. The SBC control successfully increases the power supplied by the fuel cell, making it work near or at full power. The fuel cell was forced to operate at $22 \mathrm{~kW}$ gross power. Fig. 13 shows the motor, fuel cell and battery currents. The SBC control made the fuel cell work at high current, reaching 100 A during 3 and a half minutes of the take-off and climb. Fig. 14 shows the bus, fuel cell and battery voltages on the left abscise, and the SBC output voltage on the right abscise. The difference between the fuel cell voltage and the bus voltage is the voltage boosted by the SBC. The battery and bus voltages coincide. The output voltage of the $\mathrm{SBC}$ is maximum during the first 3 and a half minutes and decreases afterwards. At the beginning, the SBC attempts to make the fuel cell operate at the programmed current (100 A), but it is limited by its maximum output voltage $(26 \mathrm{~V})$. Therefore, by boosting its maximum voltage it makes operate the fuel cell $26 \mathrm{~V}$ below the bus voltage. However, it is not enough to set the fuel cell voltage to the voltage corresponding to the programmed current $(216 \mathrm{~V})$. While the battery discharges with time, the difference between the fuel cell desired voltage and the bus voltage decreases, and so, the voltage to be boosted. Once the battery is discharged enough, the $\mathrm{SBC}$ is able to force the fuel cell to operate at $100 \mathrm{~A}$, and the output voltage of the SBC decreases with time, following the further battery discharge.

Fig. 15 and Fig. 16 show the comparison between simulated and measured powers and battery capacity,

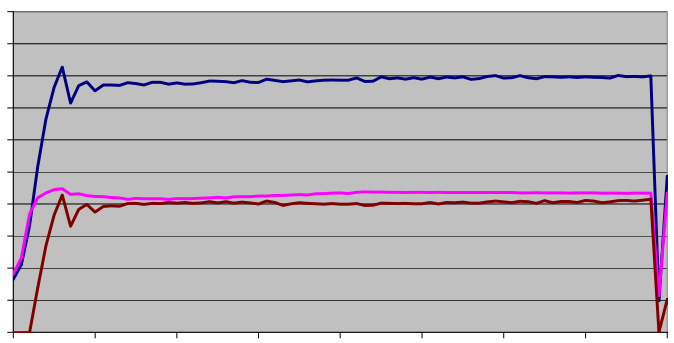

$-\mathrm{P}$ ot $-\mathrm{Pfc}-\mathrm{P}$ att

Figure 12. Measured powers with regulated hybrid source
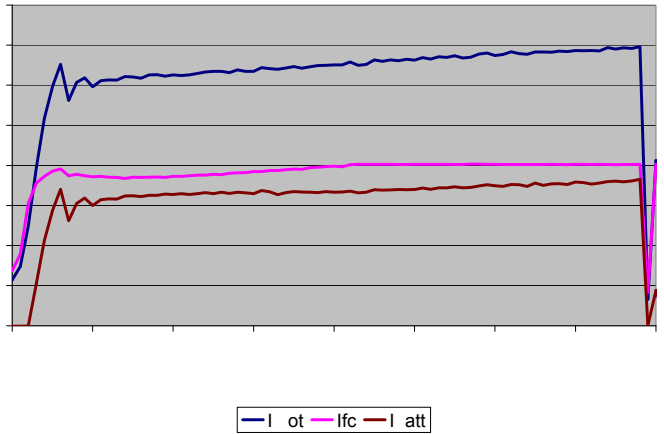

Figure 13. Measured currents with regulated hybrid source

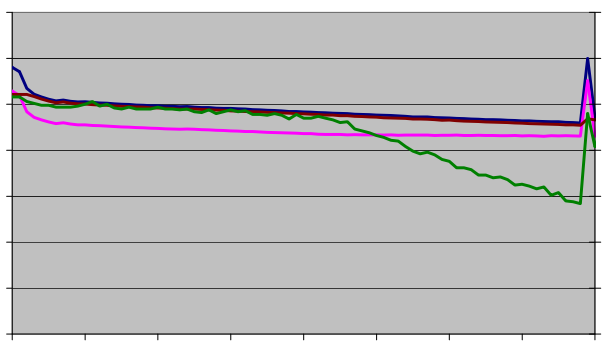

$$
-\mathrm{V}-\mathrm{vfc}-\mathrm{V} \text { att }-\mathrm{v} \mathrm{c}
$$

Figure 14. Measured voltages with regulated hybrid source

respectively. The simulation results are in close agreement with the test results.

The models can compare the battery savings for the regulated versus the unregulated architecture. For a typical take off and climb (40 kW motor power for $7 \mathrm{~min}$ ) a regulation forcing the fuel cell to operate at $22 \mathrm{~kW}$ of gross power could allow a battery capacity saving of 440 Wh or $2 \mathrm{Ah}$; and a regulation forcing the fuel cell to operate at $23 \mathrm{~kW}$ of gross power could allow a battery capacity saving of $540 \mathrm{Wh}$ or $2.5 \mathrm{Ah}$.

Taking a typical energy density of $70 \mathrm{Wh} / \mathrm{kg}$ for Li ion batteries, the capacity saving would correspond to a weight saving of $6.3 \mathrm{~kg}$ when forcing the fuel cell at 22 $\mathrm{kW}$ and $7.7 \mathrm{~kg}$ when forcing the fuel cell at $23 \mathrm{~kW}$. On the other hand, taking a typical handling power density of converters of $0.5 \mathrm{~kW} / \mathrm{kg}$, including heat-sinks, the additional weight due to the converters would correspond to $6 \mathrm{~kg}$. The additional hydrogen mass consumed by the 


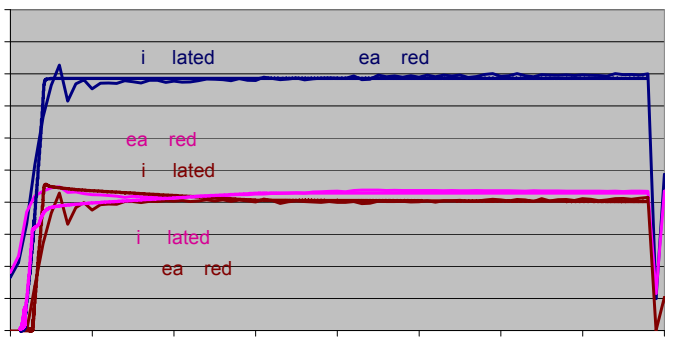

$-\mathrm{P}$ ot $-\mathrm{Pfc}-\mathrm{P}$ att

Figure 15. Comparison of simulation and test results for powers for the regulated architecture during take-off and climb
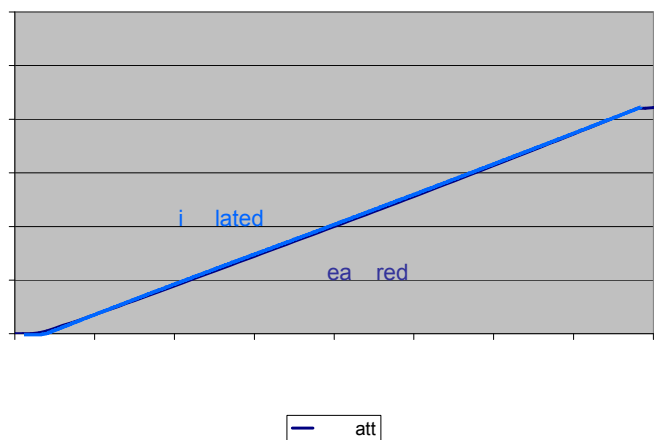

Figure 16. Comparison of simulation and test results for battery capacity for the regulated architecture during take-off and climb

fuel cell is no higher than $50 \mathrm{~g}$ in both cases. Therefore, for this particular system and this particular application, the total weight saving would correspond to approximately $0.3 \mathrm{~kg}$ when forcing the fuel cell at $22 \mathrm{~kW}$ and $1.7 \mathrm{~kg}$ when forcing the fuel cell at $23 \mathrm{~kW}$. The weight savings would increase with the duration of the operation.

The models can also compare the time the hybrid power source can supply a constant power while avoiding the fuel cell power exceeding a programmed limit in the throttle conditioning control.

In the unregulated architecture, the natural distribution makes the fuel cell increase its power contribution within time, following the battery discharge. Once the fuel cell reaches the programmed power limit, the fuel cell power would carry on increasing while the battery power would carry on decreasing. However, at this point, the throttle control starts decreasing the torque command sent to the inverter motor, succeeding to decrease the power demanded by the motor.

In the regulated architecture, the fuel cell is forced to operate at its power limit, and, once the battery gets discharged enough, fuel cell power would increase over its limit while the battery power would continue decreasing. Once again, the throttle control avoids the fuel cell going beyond the programmed limit. However, due to the battery savings, this time is reached later than in the unregulated architecture.

Therefore, by using a regulated architecture, the hybrid power source will supply a constant power demand for longer.
The simulations results show that for a typical take-off and climb power rate ( $40 \mathrm{~kW}$ motor power) and when the fuel cell power limit is programmed to be $22 \mathrm{~kW}$ gross power, the regulated hybrid power source can supply the constant power for 1 more minute (from 8 and a half minutes to 9 and a half minutes). For the same typical take-off and climb, when the fuel cell power limit is programmed to be $23 \mathrm{~kW}$ gross power, the regulated hybrid power source can supply the constant power for 1 and a half more minutes (from 9 and a half minutes to 11 minutes).

\section{EVALUATION OF BOTH ARCHITECTURES}

In this section the advantages and disadvantages of both architectures are discussed according to different criteria that might be crucial depending of the particular application:

- Complexity: The unregulated architecture is simpler. It does not require any additional wide input voltage-wide output voltage dc-dc modules and the implementation of a current loop to control them under all different conditions.

- Reliability: Due to its simplicity, the unregulated architecture is more reliable in terms of components failure. Although protections are necessary to avoid damaging the sources with heavy load conditions, that could be caused by any fault, those are also necessary in the case of the regulated architecture.

- Efficiency: The efficiency of the unregulated architecture is higher than that of the regulated architecture since the power of the fuel cell is not processed by any dc-dc converter.

- Cooling: Related to the efficiency, the cooling requirements for the unregulated architecture are lower than those of the regulated architecture because of the lower losses.

- Impact on battery size: The regulated architecture allows minimizing the size of the battery that supports the fuel cell during the take-off and climb because it forces the fuel cell to supply all the load current up to its programmed limit. In this way, the battery capacity is minimized.

- Weight: Although the weight of the regulated architecture is penalized by the dc-dc converters, the benefit of having a smaller battery can overcome this weight penalty. As a consequence, the regulated architecture system can be lighter.

- Duration: Since the regulated architecture saves some battery energy, the hybrid power source is able to supply a certain power level for longer without exceeding the fuel cell power capabilities. The total energy of the hybrid power source is then enhanced.

- Robustness: Since in the unregulated architecture the load sharing between the fuel cell and the battery is strongly dependent on their parameters (state of charge, internal impedance, capacity, open circuit voltage, temperature, etc.), its behavior is dependent on the nominal tolerances, variation with temperature and age, etc. In the case of the regulated architecture, the series boost converter 
and the control loop make the behavior of the system almost insensitive to those variations.

\section{CONCLUSION}

Two different architectures can be used in a hybrid power source that comprises a PEM fuel cell and a Li ion battery. The unregulated architecture implies a natural balance between the sources. The regulated architecture controls the power supplied by each source by means of a serial boost converter connected to the distribution bus in series with the fuel cell. The output voltage of the converter is regulated through a control loop that maximizes the fuel cell power.

Both proposed architectures offer advantages and disadvantages. The unregulated architecture is simpler, more reliable, more efficient and needs a simpler cooling. The regulated architecture discharges less the battery, allowing the use of smaller batteries, and, thus, it offers a weight reduction possibility; another consequence of the battery energy savings is that the hybrid power source can supply a certain power level for longer without exceeding the fuel cell power capabilities, maximizing, this way, the total energy of the hybrid power source; moreover, the regulated hybrid power source has a more reproducible behavior because it has a lower dependency of the external conditions, such as temperature, ageing or operation.

Both concepts have been simulated, implemented and thoroughly tested in the Fuel Cell Demonstrator Airplane, the first manned prototype to prove straight level flight with fuel cell power. The unregulated architecture was more appropriate for the demonstrator mainly because in this particular application the battery energy saving, and so the possible weight reduction, was not significant enough. The increase of the take-off and climb time offered by the regulated architecture was neither required because 5 minutes were sufficient to reach the cruise altitude. On the other hand, the safety and reliability of the system were crucial. The unregulated configuration was inherently more reliable due to its simplicity and did not force the fuel cell to operate at its maximum power output reducing the risk of a fuel cell trip off during take-off and climb and decreasing the amount of water and hydrogen to be carried on-board during the test flights. In addition, a bigger battery could provide the full power for a shorter take-off and climb in the case of a fuel cell trip off, allowing the aircraft to climb up to a safe altitude.

\section{REFERENCES}

[1] Invention disclosure F710000006, Energy optimization of a fuel cell/battery hybrid power source, E. Bataller, J. Oliver, O. García, filed in Q1 2007.

[2] The Boeing Fuel Cell Demonstrator Airplane, N. Lapeña-Rey, J. Mosquera, E. Bataller and F. Ortí, SAE 2007 Aerotech Congress \& Exhibition (Publication Number: 2007-01-3906).

[3] Environmentally Friendly Power Sources for Aerospace Applications, N. Lapeña-Rey, J. Mosquera, E. Bataller and F. Ortí, $10^{\text {th }}$ Grove Fuel Cell Symposium (Publication Number: POWERD-07-02171). 